\title{
The Effect of Whole Body Vibration Exposure on Muscle Function in Children With Cystic Fibrosis: A Pilot Efficacy Trial
}

\author{
Kaitlin O'Keefe ${ }^{\mathrm{a}}$, Rhonda Orr ${ }^{\mathrm{a}}$, Peite Huang ${ }^{\mathrm{a}, \mathrm{f}}$, Hiran Selvadurai ${ }^{\mathrm{b}, \mathrm{c}}$, Peter Cooper ${ }^{\mathrm{b}, \mathrm{c}}$, \\ Craig Frank Munns, , d, Maria A Fiatarone Singha, c, e
}

\begin{abstract}
Background: To examine the effects of whole body vibration (WBV) exposure on muscle function in children with Cystic Fibrosis (CF). Non-randomised controlled cross-over trial.

Methods: The setting was home-based WBV exposure. The participants were children ( $8-15$ years $)$ with $C F(n=7)$. Intervention: participants served as their own controls for the first four weeks (usual care), then underwent four weeks of parentally-supervised home-based WBV exposure followed by four weeks washout (usual care). The WBV exposure consisted of 20 - 30 minutes of intermittent (1 min vibration: 1 min rest) exposure on a Galileo platform (20 - 22Hz, $1 \mathrm{~mm}$ amplitude) 3 days/week. The primary outcome measures of absolute and relative lower body (leg extension (LE), leg press (LP)), upper body (chess press (CP)) strength and power, and power were measured at baseline, and weeks 4,8 and 12. Secondary exploratory outcomes were cardiorespiratory fitness, pulmonary function and health-related quality of life.
\end{abstract}

Results: Six participants completed the training without adverse events. Muscle function changes following WBV exposure were not statistically significant. However, moderate-to-large relative effect sizes (ES) favouring WBV were evident for leg extension strength $(\mathrm{ES}=0.66(-0.50,1.82)), \mathrm{LP}$ relative strength $(\mathrm{ES}=0.92$ $(-0.27,2.11))$, leg press peak power $(\mathrm{ES}=0.78(-0.50,2.07))$ and

\footnotetext{
Manuscript accepted for publication February 6, 2013

${ }^{\mathrm{a}}$ Exercise, Health and Performance, Faculty Research Group, Faculty of Health Sciences, University of Sydney, Australia

bepartment of Respiratory Medicine, The Children's Hospital at Westmead Westmead, Sydney 2145, New South Wales, Australia ${ }^{\mathrm{c} S}$ Sydney Medical School, University of Sydney, Australia

${ }^{\mathrm{d}}$ Department of Endocrinology and Diabetes, The Children's Hospital at Westmead, Sydney 2145, New South Wales, Australia

${ }^{e}$ Hebrew Senior Life and Jean Mayer USDA Human Nutrition Centre on Aging at Tufts University, Boston, MA, USA

${ }^{\mathrm{f}}$ Corresponding author: Peite Huang, Department: Faculty of Health Sciences, C42 - Cumberland Campus, University of Sydney,

Lidcombe, NSW 2141, Australia. Email: hpat.tw@gmail.com
}

doi: http://dx.doi.org/10.4021/jocmr1137w
CMJ height $(\mathrm{ES}=0.60(-0.56$ to 1.76$))$.

Conclusions: The results from this first controlled trial indicate that WBV may be a potentially effective exercise modality to safely increase leg strength and explosive power in children with CF. Potentially clinically relevant changes support continued investigation of the efficacy, mechanism and feasibility of this intervention in future large-scale studies.

Keywords: Cystic Fibrosis; Children; Vibration; Muscle function; Muscle power

\section{Introduction}

Cystic fibrosis (CF) is an autosomal recessive disease [1]. Pubescent children with CF are significantly less active than healthy controls $[2,3]$. With the progression of this multisystem disease, many patients experience exercise intolerance [4], and less-fit patients are reported to have a poorer prognosis than their aerobically-fit counterparts [5]. Currently, exercise is advocated as a critical part of the care-plan for patients with $\mathrm{CF}$, due to its benefits to aerobic [6-8] and anaerobic fitness [9], respiratory function [10, 11], peripheral muscle strength $[1,6,7,10]$ and health-related quality of life (HRQOL) [9, 12].

Patients with CF have reduced muscle strength when compared to healthy age-matched individuals [13, 14], however there is little consensus as to the aetiology of this muscle weakness [15]. Some studies suggest impairments in the muscle quality and force-generating capacity [16-18], whilst others report that smaller peripheral muscle mass is responsible for the decreased strength [19-21]. Physical inactivity $[22,23]$, poor nutritional status $[15,24]$, corticosteroid therapy $[15,25]$, hypoinsulinaemia due to pancreatic dysfunction $[26,27]$, and increased resting energy expenditure [28, 29] may all contribute. It is most likely, however, that the primary determinants of reduced fat-free mass are the inflammatory and catabolic responses to chronic lung disease and infection and corticosteroid treatment $[22,30]$. As CF life expectancy has increased to an average of 37 years [31], sarcopenia, and 


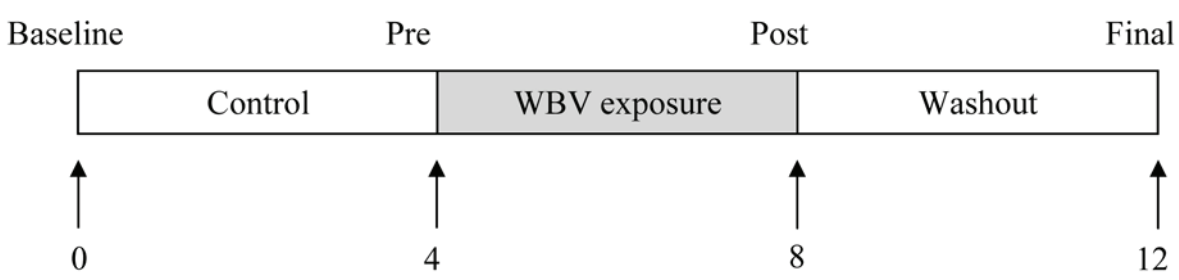

Time (weeks)

Figure 1. Study Design. The arrows indicate 4 test occasions over the twelve weeks. Baseline values were obtained at week 0 , at end of Control period testing at week 4, at end of Vibration exposure period at week 8, and at end of Washout period between week 8 and at week 12. The black rectangle indicates the training weeks, and the white rectangle shows when there was no applied intervention. Usual care was given throughout the twelve weeks. In the Control and Washout periods, participants continued usual physical activity.

CF-related diabetes mellitus and osteoporosis are now emerging in this population, making it even more pertinent that interventions can both treat and prevent these conditions.

Recently, whole body vibration (WBV) has received much attention for its purported ability to improve bone mineral density (BMD) [32], flexibility [33, 34], balance and mobility [35, 36], aerobic capacity [37] and notably, muscle function $[38,39]$. WBV has been theorised to act on muscle function in part via the stimulation of muscle spindles, leading to the excitation of alpha motor neurons, which contract the motor units. A tonic vibration reflex, or tonic contraction of the muscle results [40]. As acute exacerbations of $\mathrm{CF}$ contribute to fatigue and may preclude participation in traditional modalities of exercise, one potential utility of this modality of training is its non-exertional nature. It could theoretically be a useful alternative/adjunct to traditional resistance or aerobic training exercises, as it can be performed by those unable to exercise, and even continued during periods of severe dyspnoea, illness and hospitalisation for treatment of CF and its co-morbidities.
Recently, two uncontrolled trials have investigated home-based WBV exposure with concomitant muscle strengthening exercise in adults with CF [41, 42]. In the first [42], six months of continuous WBV exposure (6 - 12 minutes; $12-26 \mathrm{~Hz}$ ), five days/week in eleven adults aged 29 - 38 years resulted in small non-significant improvements in muscle power $4.7 \%$ (range $-16.4 \%$ to $+74.5 \%$ ) and velocity $6.6 \%$ (range $-0.9 \%$ to $+48.3 \%$ ), as assessed by one- and two-legged jumps on a Leonardo (Novotec Medical, Pforzheim, Germany) platform. By contrast, in the second study, three months of intermittent WBV exposure (18 minutes) five days/week in 10 adults (three males; seven females) aged 24 - 47 years significantly improved in lower-extremity muscle force and power [41]. Interpretation of these findings is limited due to the uncontrolled study designs, heterogeneous results, and most importantly, the use of a combined intervention of resistance training plus $\mathrm{WBV}$, precluding the attribution of benefits to WBV itself.

Thus, our purpose was to conduct the first controlled efficacy trial of isolated WBV exposure in children with CF.

Table 1. Training Volume and Training Intensity of the Whole Body Vibration (WBV) Program

\begin{tabular}{lllllll}
\hline Week & $\begin{array}{l}\text { Training } \\
\text { frequency } \\
\text { (days/week) }\end{array}$ & $\begin{array}{l}\text { Vibration } \\
\text { frequency }(\mathbf{H z})\end{array}$ & $\begin{array}{l}\text { Peak-to-Peak } \\
\text { Vibration } \\
\text { amplitude }(\mathbf{m m})\end{array}$ & $\begin{array}{l}\text { Vibration } \\
\text { magnitude }(\mathrm{g})\end{array}$ & $\begin{array}{l}\text { Total session } \\
\text { duration } \\
\text { (mins) }\end{array}$ & $\begin{array}{l}\text { Vibration } \\
\text { exposure } \\
\text { (mins) }\end{array}$ \\
\hline 5 & 3 & 20 & 1.0 & 1.61 & 20 & 10 \\
6 & 3 & 20 & 1.0 & 1.61 & 30 & 15 \\
7 & 3 & 22 & 1.0 & 1.95 & 30 & 30 \\
8 & 3 & 22 & 1.0 & 1.95 & 30 & 15 \\
\hline
\end{tabular}

\footnotetext{
* Formula for vibration magnitude [40]: $g=A(2 \pi f)^{2} / 9.81$, A: Peak-to-Peak Vibration amplitude (mm); f: frequency $\left(H_{z}\right) ; 9.81$

$=$ force due to gravity.
} 


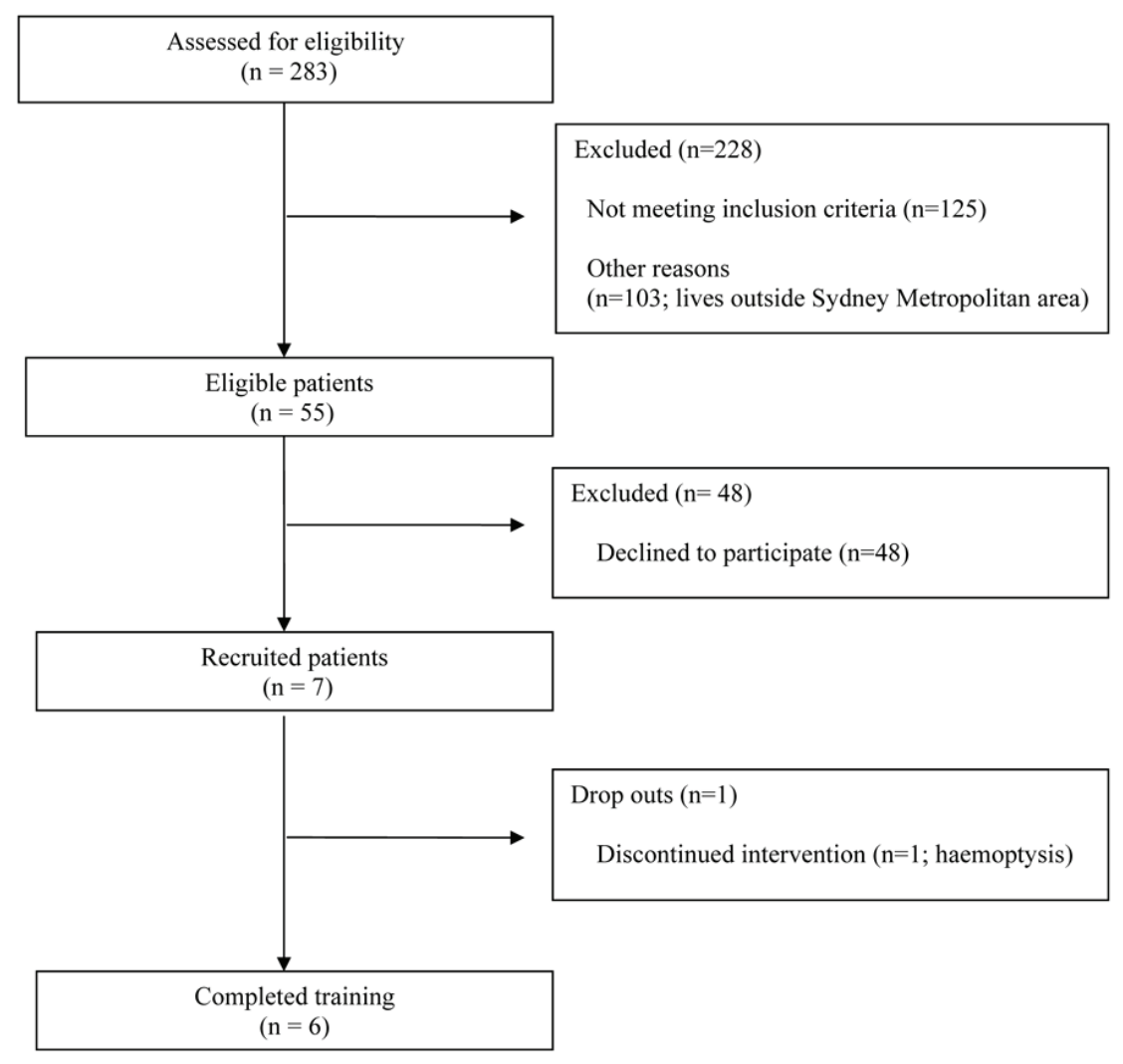

Figure 2. Flow diagram of participant recruitment.

The specific aims of this controlled cross-over trial were to: (1) assess the effect of one month of WBV exposure on muscle strength and power, maximal aerobic capacity, pulmonary function and HRQOL in children with CF; and (2) determine any residual effect of WBV exposure after a washout period; calculate effect sizes and sample size determinations for a full-scale trial.

Our primary hypothesis was that 4 weeks of WBV exposure (3 times/week) would increase muscle function relative to the preceding usual care control period in children with CF. Our secondary hypothesis was that any improvements in musculoskeletal outcomes would not be present at the end of a 4-week washout period. Additional secondary exploratory hypotheses were that WBV exposure would improve cardio-respiratory endurance performance, pulmonary function, and HRQOL.

\section{Methods}

\section{Participants}

Participants were recruited from the CF Clinic at The Children's Hospital at Westmead (CHW). Inclusionary criteria proven $\mathrm{CF}$ and $8-18$ years of age. Exclusionary criteria were contraindications to WBV [43], severe CF (forced expiratory volume in 1 minute $\left(\mathrm{FEV}_{1}<40 \%\right.$ predicted)), inability to stand unaided for 30 minutes, long bone or vertebral fracture in the past six months, past/present history of osteoarthritis, presence of CF-liver disease with portal hypertension, neuropathy or myopathy and/or vitamin D deficiency (25-hydroxyvitamin $\mathrm{D}<39 \mathrm{nmol} / \mathrm{L}$ ) in the past three months. The study was approved by CHW and The University of Sydney Human Research Ethics Committees (July 2008) and registered with the Australian New Zealand Clinical Trials Registry (number: ACTRN12609000090213). Written informed consent was obtained from all participants and parents.

\section{Study design}

This controlled cross-over trial involved four weeks each of control, WBV exposure and washout period. Randomisation of control and exposure periods was not possible due to unknown duration of WBV effect, if any. Tests were conducted at four time points: baseline, week 4 (pre), week 8 (post) and week 12 (final) as shown in Figure 1. Following the training month, testing took place $48-72$ hours after the last WBV session to avoid acute effects of vibration exposure [44, 45]. Participants were informed not to change levels of physical activity during the study. Usual medical care was continued 
Table 2. Participant Characteristics

\section{Characteristic}

Age

Sex

Anthropometry

Height $(\mathrm{cm})$

Weight ( $\mathrm{kg})$

BMI $\left(\mathrm{kg} / \mathrm{m}^{2}\right)$

Waist circumference $(\mathrm{cm})$

Health-Related Quality of Life

Total score on CFQ-R (\%) [12] (0 - 100)

Respiratory function ( $\%$ of predicted)

FEV

FVC

VC

RV

TLC

Aerobic Capacity

$\mathrm{VO}_{2}$ peak $(\mathrm{ml} / \mathrm{kg} / \mathrm{min})$

OUES [31]

Physical Performance

Countermovement jump height $(\mathrm{cm})$

Countermovement jump power (W)

Leg Extension strength (Nm)

Chest Press strength (N)

Leg Press strength $(\mathrm{N})$

Leg Extension peak power (W)

Chest Press peak power (W)

Leg Press peak power (W)
Baseline $(\mathrm{n}=7)$

$11.7 \pm 2.6$

$60 \%$ girls

$146.2 \pm 17.7$

$40.8 \pm 16.3$

$18.3 \pm 3.0$

$67.5 \pm 8.3$

83.5

$77.4 \pm 14.4$

$88.0 \pm 16.4$

$93.2 \pm 13.6$

$125.3 \pm 92.8$

$99.7 \pm 16.0$

$34.5 \pm 5.1$

$706.4 \pm 281.7$

$27.0 \pm 5.0$

$652.0 \pm 306.0$

$86 \pm 37$

$213 \pm 82$

$816 \pm 168$

$199 \pm 103$

$138 \pm 66$

$473 \pm 247$

Values are mean \pm standard deviations $(\mathrm{SD}) ; \mathrm{cm}=$ centimetre; $\mathrm{ml}=$ millimetres; $\mathrm{min}=$ minute; $\mathrm{kg}$ = kilogram; $\mathrm{cm}=$ centimetre $\mathrm{m}=$ metre $\mathrm{N}=$ Newtons; $\mathrm{Nm}$, Newton-metres; $\mathrm{W}=$ watts; $\%$ pred $=$ value reported as percent of predicted value, $1 \mathrm{RM}=$ one repetition maximum; $C F Q-R=$ cystic fibrosis questionnaire revised, where higher scores indicate better quality of life [10]; $F E V_{1}=$ forced expiratory volume in 1 second; FVC = forced vital capacity; VC = vital capacity; RV = residual volume; TLC = total lung capacity; $\mathrm{VO}_{2}$ peak = peak oxygen uptake during volitional maximum treadmill test; OUES = oxygen uptake efficiency slope; higher OUES is associated with higher aerobic capacity [31]. 
and monitored but not controlled by study investigators.

\section{Measurements}

Testing took place at CHW and The University of Sydney. The order of testing was standardised. Testing at The University of Sydney was performed by one researcher. Pulmonary function testing took place at $\mathrm{CHW}$ by one of two researchers.

\section{Primary outcomes}

\section{Muscle function (strength and power)}

Strength was assessed on Keiser pneumatic-resistance training equipment ${ }^{\mathrm{a}}$ using one repetition maximum (1RM) in three bilateral exercises: knee extension, chest press and horizontal leg press [46]. Power was measured at $60 \%$ current $1 \mathrm{RM}$, as peak power has been observed between 50 $75 \%$ 1RM [47]. The highest of three maximal explosive efforts were performed separated by 1 -minute rest was used in analyses.

\section{Counter-movement jump (CMJ) performance}

Participants performed three maximal CMJs on a force platform $^{\mathrm{b}}$. The vertical signal from the platform was sampled at $1,000 \mathrm{~Hz}$ and recorded by computer. The highest jump height and the subsequent power and ground reaction forces (GRFs) were recorded and analysed (ICC, test-retest reliability in untrained females, $r=0.99)$ [48].

\section{Secondary outcomes and descriptive characteristics}

\section{Anthropometrics}

Height $^{\mathrm{d}}$ and weight ${ }^{\mathrm{e}}$ were measured, and body mass index (BMI) $\left(\mathrm{kg} / \mathrm{m}^{2}\right)$ was calculated. Waist circumference was measured at the narrowest point between the lower costal (10th rib) border and the iliac crest. The CVs of triplicate measurements on the same day in the whole sample for height, weight, and waist circumference were $0.02 \%$, < $0.01 \%$, and $0.12 \%$, respectively.

\section{Pulmonary function}

Resting pulmonary function tests without bronchodilators including body plethysmography and spirometry were performed $^{\mathrm{c}}$ at the Respiratory Function Unit, CHW. Measures included forced expiratory volume in 1 second $\left(\mathrm{FEV}_{1}\right)$, forced vital capacity (FVC), forced mid-expiratory flow rate $\left(\mathrm{FEF}_{25-75 \%}\right)$, vital capacity (VC), total lung capacity (TLC), residual volume (RV), and RV as a percentage as TLC (RV/ TLC\%) [49].

\section{Peak aerobic capacity}

The protocol treadmill test ${ }^{\mathrm{g}}$ was a walking incremental incline design, set at current habitual gait speed (determined prior using an ultrasonic timer $)^{j}$, starting at $6 \%$ grade, increasing by $2 \%$ every minute. From $24 \%$ grade, incline was maintained and speed increased by $0.5 \mathrm{~km} / \mathrm{hr}$ each minute until voluntary exhaustion. Heart rate was monitored by 12-lead $\mathrm{ECG}^{\mathrm{h}}$, and blood pressure was taken via an automated blood pressure system synched to ECG signal every two minutesi. Continuous respiratory gas analysis and volume measurements were performed breath-by-breath ${ }^{\mathrm{k}}$ with a pneumotach attached to a Medgraphics mask ${ }^{1}$. From calorimetry data peak oxygen uptake $\left(\mathrm{VO}_{2}\right.$ peak; average of final 30 seconds of exercise) and Oxygen Uptake Efficiency Slope (OUES) [50] were calculated as measures of aerobic capacity and respiratory efficiency (OUES), where higher values are associated with better aerobic capacity.

\section{Quality of life}

HRQOL was measured with the Cystic Fibrosis Questionnaire-Revised (CFQ-R) [12]. Higher scores indicate better self-assessed quality of life. Questionnaires were interviewer-administered in private prior to any physical function assessments.

\section{Training procedure}

Participants completed a four-week home-based WBV exposure, three days/week (12 sessions) with parental supervision. An investigator supervised the first session. The protocol was intermittent (1 minute vibration:1 minute rest) and progressive (Table 1). Participants stood on a Galileo Basic Platform with arms by their sides, with a $150^{\circ}$ knee angle (slight flexion) during the exposure minute and relaxed the knee angle during the rest minute. Participants wore socks during training to prevent dampening of vibration stimulus via footwear [51], and were asked to complete a training diary and to train at the same time of day.

\section{Health status check}

A researcher conducted weekly health status checks via phone to monitor acute illness, change in medications, visits to health-care professionals, new symptoms (physical, mental, emotional), bodily pain (muscular and joint), changes in mucus clearance, appetite, body mass, possible adverse effects of testing or vibration exercise and training compliance.

\section{Statistical analysis}

Statistical analyses were performed using SPSS version $15.0^{\mathrm{n}}$. The statistical approach was to use all available data 


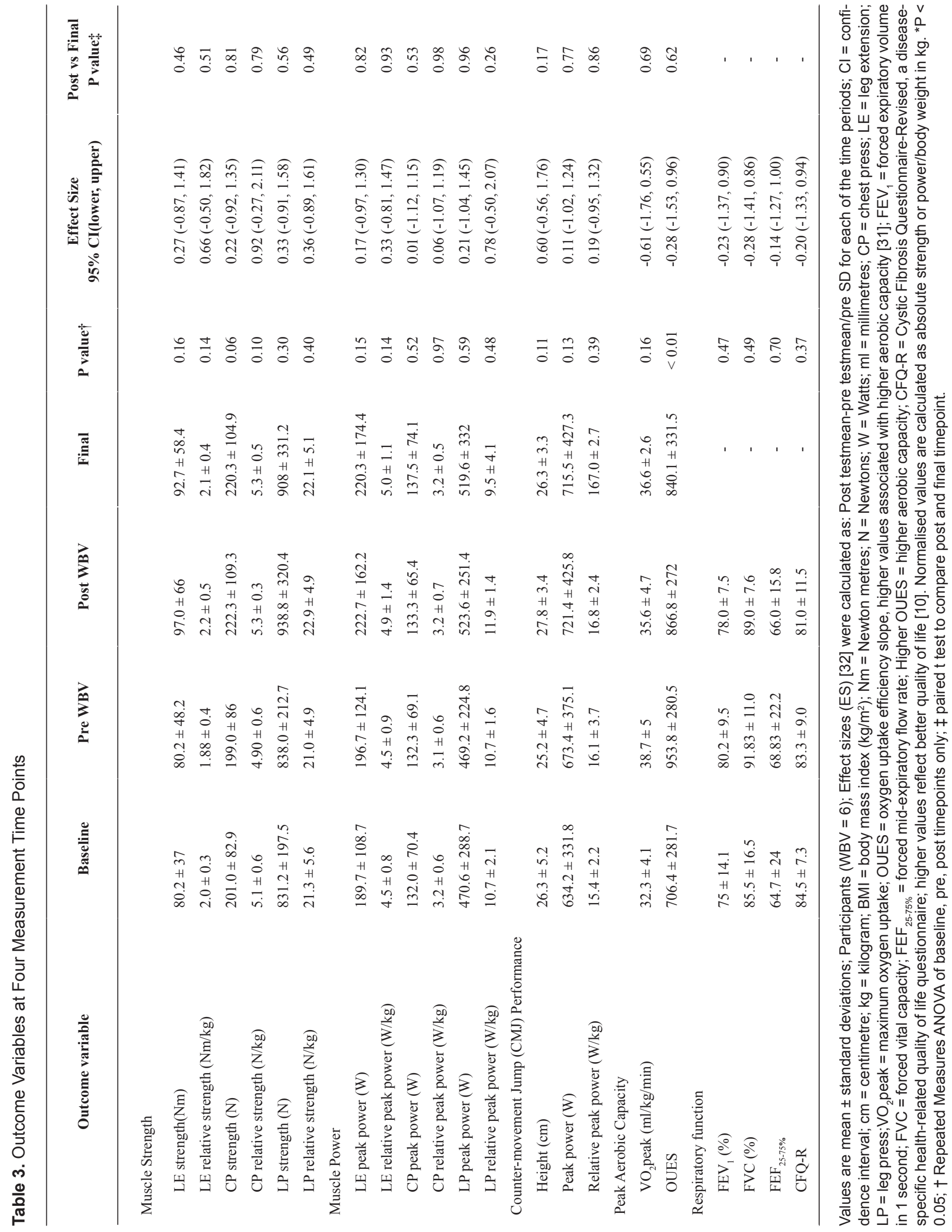


Table 4. Post-Hoc Power Calculations

\begin{tabular}{lll}
\hline Main outcomes & Effect Size & Total sample size required (n) \\
\hline LE relative strength $(\mathrm{Nm} / \mathrm{kg})$ & $0.66(-0.50,1.82)$ & 10 \\
CP relative strength $(\mathrm{N} / \mathrm{kg})$ & $0.92(-0.27,2.11)$ & 9 \\
LP relative peak power $(\mathrm{W} / \mathrm{kg})$ & $0.78(-0.50,2.07)$ & 12 \\
Counter-movement jumpheight $(\mathrm{cm})$ & $0.60(-0.56,1.76)$ & 18 \\
\hline
\end{tabular}

\begin{abstract}
*G-power software (GPower 3.0 for Windows, Germany) used to compute sample size necessary to achieve statistical significance assuming and two-sided alpha of 0.05 and a beta of 0.20 . Sample size assumes a 2-group design, with equal 1:1 allocation to each group. Power calculations were performed for the 4 variables with the largest Effect Sizes observed in this pilot study.
\end{abstract}

regardless of compliance in this efficacy analysis, but without imputation for missing data, given the small sample size. Data distributions were inspected visually and statistically for normality (skewness -1 to +1 ). Normally distributed and non-normally data were described using mean \pm standard deviations (SD) and median (range) respectively. Nonnormally distributed data were log-transformed if possible prior to use with parametric statistics. The effect of WBV exposure was examined using repeated measures analysis of variance (ANOVA) analysis including three timepoints: baseline, pre-WBV and post-WBV. Any residual adaptation to WBV exposure retained during the washout period was examined by paired t-test using post-WBV and final timepoints. Hedge's bias-corrected effect sizes (ES) [52-54] for the effect of WBV exposure were calculated as: Post tes$\mathrm{t}_{\text {mean }}-$ pre test $t_{\text {mean }}$ /pre SD for each of the time periods. The Relative ES ( $\left.=\mathrm{E}_{\text {Sintervention }}-\mathrm{E}_{\text {Scontrol }}\right)[55]$ is reported along with $95 \%$ confidence intervals (CI). Post hoc sample size calculations were performed using calculated ES of muscle outcomes [56]. Statistical significance was accepted at $\mathrm{P}<$ 0.05 .

\section{Results}

\section{Recruitment, attrition, adverse events, and compliance}

From 283 patients who attend the CF clinic at CHW, 55 living in the Sydney metropolitan area fulfilled the criterion for inclusion (Fig. 2). Seven patients (four boys, three girls) were recruited, the remaining eligible subjects were not interested. One participant withdrew following one week of training after the recurrence of haemoptysis. Vibration training was not considered by medical staff to be causative. No adverse events were reported. Compliance was $100 \%$, with participants taking, on average, $30.4 \pm 1.5$ days to complete the 12 sessions.

\section{Participant characteristics}

Baseline characteristics are reported in Table 2. The mean age of participants was $11.7 \pm 2.6$ (range $8-15$ ) years. Participants had mild to moderate $\mathrm{CF}$, with only one having any hospitalisations $(\mathrm{n}=2)$ in the previous 12 months. This patient subsequently withdrew from the study for an unrelated medical issue (haemoptysis). At baseline and throughout the study four participants required pancreatic enzyme supplementation. One participant suffering recurrent allergic broncho-pulmonary Aspergillosis required oral glucocorticoid medication.

\section{WBV exposure}

\section{Main outcomes}

\section{1) Muscle strength}

Muscle function results are presented in Table 3. No muscle strength measures changed significantly. However, non-significant trends for improvements after WBV exposure were observed for $\mathrm{CP}$ strength $(\mathrm{ES}=0.22(-0.92,1.35) ; \mathrm{P}=0.06)$, $\mathrm{CP}$ relative strength $(\mathrm{ES}=0.92(-0.27,2.11) ; \mathrm{P}=0.10)$, and LE relative strength $(\mathrm{ES}=0.66(-0.50,1.82) ; \mathrm{P}=0.14)$. It is notable that most of the trends were seen in relative measures of strength (normalised to body weight), suggesting that it was changes in neuromuscular function rather than increases in muscle mass which likely explain these effects after only four weeks of WBV exposure.

\section{2) Muscle power}

No muscle power outcomes changed significantly. However, among these power outcomes, LE relative power was close to significance $(\mathrm{P}=0.14)$ with a small $\mathrm{ES}=0.33(-0.81,1.47)$ and the ES for LP relative power was moderate-large $(0.78$ 
$(-5.0,2.07))$. As noted above for muscle strength, it is the relative power outcomes, which tended to improve, as expected. The functional test for muscle power, CMJ height, improved by $12 \%$ compared to control after WBV exposure, and although not significant $(\mathrm{P}=0.11)$ the $\mathrm{ES}$ was moderate $\mathrm{ES}=(0.60(-0.56,1.76))$.

\section{Secondary outcomes}

There were no significant improvements after WBV exposure in pulmonary function measures or HRQOL (Table 3). Unexpectedly, OUES declined significantly after WBV exposure $(\mathrm{P}<0.001)$, however $\mathrm{VO}_{2}$ peak did not change significantly over the course of the study.

\section{Washout}

There were no significant differences in any outcome measures in the washout period compared to the measurement taken at the end of WBV exposure.

\section{Discussion}

This is the first controlled trial to our knowledge assessing the effects of WBV exposure on muscle function, cardiorespiratory fitness, pulmonary function and quality of life in individuals with $\mathrm{CF}$, and also the first trial ever to assess the effects of WBV exposure in children with CF. In addition, this is the first report of the effects of an extended washout period on potential adaptations to WBV. Four weeks of home-based WBV exposure had no significant effect on any primary or secondary outcome measures. However, several indices of upper and lower body relative strength and power tended to improve, with moderate-large effect sizes in some cases.

\section{Comparison to studies of WBV in adults with CF}

The magnitude of the changes in muscle strength, power, and CMJ height we observed were similar to those reported in trials investigating WBV exposure and muscle function in adults with CF [41, 42]. Rietschel et al [41] reported that muscle power, force and velocity increased significantly after three months of training. Roth et al [42] also showed improved muscle power and velocity after 6 months of training. In Roth's study, adults with CF improved CMJ height by $6.1 \%$ (range $-25.1 \%$ to $+63.9 \%)$ compared with $12 \%(0 \%$ to $25 \%$ ) observed in our children with CF. Although these two adult studies reported significant improvements after WBV exposure, there are a number of design features that limit the robustness of these data. Most importantly, there were no control groups and both studies combined WBV exposure with lower body exercise on the platform, thus precluding attribution of benefit to WBV alone. Only one of the studies reported statistical analysis of their data [41].

\section{Effects on muscle strength}

Ours is the first study to our knowledge to report a tendency for increased upper body strength $(\mathrm{ES}=0.92)$ in patients with $\mathrm{CF}$ following WBV exposure. Our finding raises the possibility that WBV exposure could be beneficial to other upper body musculature such as the highly clinically relevant respiratory muscles. Children with $\mathrm{CF}$ rely heavily on recruitment of accessory respiratory musculature when experiencing breathing difficulties associated with pulmonary infections and progressive lung disease. Future long-term trials of WBV are needed to directly assess potential benefits to respiratory muscle function as well as rate and severity of pulmonary infections in this cohort.

\section{Effects on muscle power}

This is the first report of study in CMJ in a clinical cohort after isolated WBV exposure. Surprisingly the improvement in CMJ height (12\%) reported in our study was comparable to significant increases found after WBV with concomitant exercise in untrained females [57], young skiers [58], and healthy young adults [39]. Although none of the muscle power measures on the resistance machines changed significantly, the change in LP power, the closest measure to CMJ height, had a moderate-large ES of 0.78. The purported mechanism underlying the increase in explosive power after WBV exposure is that the vibration evokes reflex muscle fibre contractions, which in turn increases the efficiency of motor unit activation $[40,58]$. It should be noted that the power measured in CMJ test allows the subject to vary both force generation as well as velocity during the movement, whereas with the pneumatic resistance machines, the load is fixed at $60 \%$ of peak strength, and the subject attempts to move it as rapidly as possible. It is possible that these differences in test requirements explain the somewhat variable effect of WBV on power outcomes in this study.

\section{Effects on cardiorespiratory fitness}

Two prior studies in healthy adults [37, 59] have shown that cardiorespiratory fitness may improve after WBV exposure, although one of them used concomitant static and dynamic exercises on the platform, including stepping on and off it [59]. Contrary to this literature, and to our hypotheses, both aerobic capacity $(\mathrm{P}=0.16)$ and OUES $(\mathrm{P}<0.01)$ declined over the course of the WBV exposure. As there was no familiarisation test prior to baseline, it is likely that the apparent "gain" during the control period represents a learning effect. The average $\mathrm{VO}_{2}$ peak at week 4 was comparable to values found in the literature for a clinical cohort of this age. For example, aerobic capacity in a cohort of 7 to 17 year old 
patients with CF averaged $40.2 \mathrm{ml} / \mathrm{kg} / \mathrm{min}[60]$. Also, as it is an effort-dependent test, standardising the performance across time-points can be difficult [15], and this may have contributed to the $7.3 \%$ decrease following WBV exposure.

\section{Effects on pulmonary function}

Although no significant improvements in lung function were reported, this is not uncommon in exercise studies of lung diseases, as clinical benefits are generally derived from musculoskeletal rather than respiratory adaptations [1]. In-patient exercise programs in CF have failed to find any significant changes in pulmonary function following approximately two [61] or three [8] week interventions. Similarly, the two studies that have assessed WBV and exercise in adult patients with $\mathrm{CF}$ also reported no change to lung function following either three [41] or six [42] months of exposure. Generally, more than 12 months is required to adequately assess changes in respiratory function following exercise interventions $[4,62]$.

\section{Effect of washout period}

We hypothesised that any adaptations to short term WBV exposure over four weeks would be relatively transient, as they would not be explained by changes in body composition, but likely related to acute changes in neuromuscular recruitment over repetitive bouts. This view is supported by our observation that primarily relative strength and power (normalised to body mass) exhibited trends towards improvement, precisely what one would expect if muscle mass was unchanged, but the force/power generating capacity per unit muscle was increased by WBV. Unexpectedly, however, we observed no significant difference in any outcome measures four weeks after WBV exposure ceased compared to immediately postWBV results. This suggests that the moderate-large ES of the changes seen in relative $\mathrm{CP}$ and LE strength, relative LP power, and CMJ height after WBV were maintained for four weeks without additional exposure. It is possible that changes in neural recruitment patterns were somehow sustained despite withdrawal of the stimulus. It is also possible, and perhaps more likely, that repeated testing on four occasions across the study resulted in a learning/training effect on the apparati in these otherwise relatively sedentary children, such that the expected decay over the withdrawal period was masked, resulting in no change between weeks 8 and 12. We are unaware of similar time course studies after WBV withdrawal, and more information is needed on this aspect of exposure, as well as other aspects of WBV including optimal duration, frequency, intensity of $g$ forces utilised, and dose required for maintenance.

\section{Study limitations}

The primary limitation of the study was sample size, likely resulting in type II errors for many of our outcomes. Thus, as expected, due to the study's intended pilot nature, our findings were not statistically significant for most outcomes. Post-hoc power calculations of the main outcomes with moderate to high ESs (Table 4) indicated that between 9 and 18 subjects in total (if control and intervention groups were separate) would be needed to demonstrate significance.

We acknowledge other limitations to our design. There was no blinded outcome assessor. Treatment order was not randomised, as we could not exclude the possibility of a carry-over effect. A lack of familiarisation tests could have resulted in learning effects at follow-up which could have masked decay after withdrawal. We had no direct measures of body composition, muscle metabolism, or neural activation. Four weeks of WBV exposure may not have been sufficient to maximally stimulate musculoskeletal adaptations. The optimal dose of WBV for muscle function has not been determined in this population in terms of $\mathrm{g}$ forces, intermittent vs. continuous exposure, duration and/or frequency of exposure. Positioning of the knees while standing, placement of hands on a support rail connected to the vibrating platform, timing relative to bedtimes, meals, treatments or other activities, and use of concomitant exercises are all variables that require further study.

\section{Conclusions and future directions}

Our results suggest the potential for WBV exposure to improve both upper and lower body strength and power, although the findings are clearly preliminary and in need of replication and expansion in appropriately powered studies. With the life expectancy of the CF population increasing, sarcopenia and associated muscle dysfunction related to the disease and pharmacologic therapy with glucocorticoids will become an increasingly important clinical problem, WBV should also be examined in older patients and those with more severe lung dysfunction, as they are even more likely to be inactive than children with $\mathrm{CF}$ and have greater exercise intolerance and co-morbidity, and thus may potentially benefit more from the low exertion nature of WBV. A training program of longer duration should be investigated, with testing performed periodically over the study duration to monitor rates of change. With longer intervention duration, changes in muscle size and morphology should be assessed, to examine whether WBV can induce hypertrophy, as reported in one [63], but not another [64], long-term study. Given the large effect size we observed in upper body relative strength changes, future WBV research should include more measures of upper body muscle function including respiratory muscle function, to investigate the reproducibility and clinical utility of these findings. Dose-response characteristics and detraining effects remain to be clarified, as well as clinical benefits and changes in quality of life for this vulnerable cohort. 


\section{Acknowledgement}

This paper represents partial fulfilment of an Honours degree for Kaitlin O'Keefe within the Discipline of Exercise and Sport Science, Faculty of Health Sciences, University of Sydney. This study was supported by a Cumberland Research Grant to Dr. Rhonda Orr from The Faculty of Health Sciences, The University of Sydney. We thank the staff at Respiratory Function Unit and CF Clinic of CHW for their medical assistance, Mr. Ray Patton and Ms. Kylie Anderberg for their technical assistance, and the participants and parents for their participation and dedication throughout the study.

\section{Suppliers}

${ }^{a}$ Keiser Sports Health Equipment, Inc., Fresno, CA. ${ }^{\mathrm{b}}$ Kistler 9281B, Wintertur, Switzerland. 'Sensormedics 2000; Sensormedics, Yorba Linda, CA. 'Stadiometer; Holtain Limited, Crymmych Pembs., UK. ${ }^{e}$ Electronic scale; HW-100K, A\&D Bench Scales, Bradford, MA. 'Lufkin steel tape measure, W606 PM. "Quinton Q-Stress TM55 Treadmill, Quinton Cardiology Systems, Inc; Bothell, WA, U.S.A. ${ }^{\text {hQuinton }}$ 4500 Stress Test Monitor, Quinton Cardiology Systems, Inc; Bothell, WA, U.S.A. 'Quinton Automatic BP monitor model 412; Bothell, WA, U.S.A. 'Ultratimer, DCPB Electronics; Glasgow, Scotland. kUltima PFX Series, Medgraphics; St. Paul, Minnesota, U.S.A. 'Pat. \#6718982, Taiwan. ${ }^{\text {mNovotech }}$ Medical, Pforzheim, Germany. "Version 15.0 for Windows, SPSS Inc. Chicago, IL. ${ }^{\circ}$ GPower 3.0 for Windows, Germany. http://www.psycho.uni-duesseldorf.de/abteilungen/aap/ gpower3

\section{References}

1. Orenstein DM, Hovell MF, Mulvihill M, Keating KK, Hofstetter CR, Kelsey S, Morris K, et al. Strength vs aerobic training in children with cystic fibrosis: a randomized controlled trial. Chest. 2004;126(4):1204-1214.

2. Buntain HM, Greer RM, Schluter PJ, Wong JC, Batch JA, Potter JM, Lewindon PJ, et al. Bone mineral density in Australian children, adolescents and adults with cystic fibrosis: a controlled cross sectional study. Thorax. 2004;59(2):149-155.

3. Selvadurai HC, Blimkie CJ, Cooper PJ, Mellis CM, Van Asperen PP. Gender differences in habitual activity in children with cystic fibrosis. Arch Dis Child. 2004;89(10):928-933.

4. Orenstein DM, Higgins LW. Update on the role of exercise in cystic fibrosis. Curr Opin Pulm Med. 2005;11(6):519-523.

5. Nixon PA, Orenstein DM, Kelsey SF, Doershuk CF. The prognostic value of exercise testing in patients with cys- tic fibrosis. N Engl J Med. 1992;327(25):1785-1788.

6. Orenstein DM, Franklin BA, Doershuk CF, Hellerstein HK, Germann KJ, Horowitz JG, Stern RC. Exercise conditioning and cardiopulmonary fitness in cystic fibrosis. The effects of a three-month supervised running program. Chest. 1981;80(4):392-398.

7. Gulmans VA, de Meer K, Brackel HJ, Faber JA, Berger R, Helders PJ. Outpatient exercise training in children with cystic fibrosis: physiological effects, perceived competence, and acceptability. Pediatr Pulmonol. 1999;28(1):39-46.

8. Selvadurai HC, Blimkie CJ, Meyers N, Mellis CM, Cooper PJ, Van Asperen PP. Randomized controlled study of in-hospital exercise training programs in children with cystic fibrosis. Pediatr Pulmonol. 2002;33(3):194-200.

9. Klijn PH, Terheggen-Lagro SW, Van Der Ent CK, Van Der Net J, Kimpen JL, Helders PJ. Anaerobic exercise in pediatric cystic fibrosis. Pediatr Pulmonol. 2003;36(3):223-229.

10. Zach M, Oberwaldner B, Hausler F. Cystic fibrosis: physical exercise versus chest physiotherapy. Arch Dis Child. 1982;57(8):587-589.

11. Strauss GD, Osher A, Wang CI, Goodrich E, Gold F, Colman W, Stabile M, et al. Variable weight training in cystic fibrosis. Chest. 1987;92(2):273-276.

12. Quittner AL. Measurement of quality of life in cystic fibrosis. Curr Opin Pulm Med. 1998;4(6):326-331.

13. Hussey J, Gormley J, Leen G, Greally P. Peripheral muscle strength in young males with cystic fibrosis. J Cyst Fibros. 2002;1(3):116-121.

14. Pinet C, Cassart M, Scillia P, Lamotte M, Knoop C, Casimir G, Melot C, et al. Function and bulk of respiratory and limb muscles in patients with cystic fibrosis. Am J Respir Crit Care Med. 2003;168(8):989-994.

15. Barry SC, Gallagher CG. Corticosteroids and skeletal muscle function in cystic fibrosis. J Appl Physiol. 2003;95(4):1379-1384.

16. de Meer K, Jeneson JA, Gulmans VA, van der Laag J, Berger R. Efficiency of oxidative work performance of skeletal muscle in patients with cystic fibrosis. Thorax. 1995;50(9):980-983.

17. de Meer K, Gulmans VA, van Der Laag J. Peripheral muscle weakness and exercise capacity in children with cystic fibrosis. Am J Respir Crit Care Med. 1999;159(3):748-754.

18. Moser C, Tirakitsoontorn P, Nussbaum E, Newcomb R, Cooper DM. Muscle size and cardiorespiratory response to exercise in cystic fibrosis. Am J Respir Crit Care Med. 2000;162(5):1823-1827.

19. Elkin SL, Williams L, Moore M, Hodson ME, Rutherford OM. Relationship of skeletal muscle mass, muscle strength and bone mineral density in adults with cystic fibrosis. Clin Sci (Lond). 2000;99(4):309-314.

20. Enright S, Chatham K, Ionescu AA, Unnithan VB, Shale 
DJ. The influence of body composition on respiratory muscle, lung function and diaphragm thickness in adults with cystic fibrosis. J Cyst Fibros. 2007;6(6):384-390.

21. Lands LC, Heigenhauser GJ, Jones NL. Respiratory and peripheral muscle function in cystic fibrosis. Am Rev Respir Dis. 1993;147(4):865-869.

22. Ionescu AA, Evans WD, Pettit RJ, Nixon LS, Stone MD, Shale DJ. Hidden depletion of fat-free mass and bone mineral density in adults with cystic fibrosis. Chest. 2003;124(6):2220-2228.

23. Moorcroft AJ, Dodd ME, Webb AK. Long-term change in exercise capacity, body mass, and pulmonary function in adults with cystic fibrosis. Chest. 1997;111(2):338343.

24. Boucher GP, Lands LC, Hay JA, Hornby L. Activity levels and the relationship to lung function and nutritional status in children with cystic fibrosis. Am J Phys Med Rehabil. 1997;76(4):311-315.

25. Pinet C, Scillia P, Cassart M, Lamotte M, Knoop C, Melot C, Estenne M. Preferential reduction of quadriceps over respiratory muscle strength and bulk after lung transplantation for cystic fibrosis. Thorax. 2004;59(9):783789.

26. Botton E, Saraux A, Laselve H, Jousse S, Le Goff P. Musculoskeletal manifestations in cystic fibrosis. Joint Bone Spine. 2003;70(5):327-335.

27. Costa M, Potvin S, Hammana I, Malet A, Berthiaume Y, Jeanneret A, Lavoie A, et al. Increased glucose excursion in cystic fibrosis and its association with a worse clinical status. J Cyst Fibros. 2007;6(6):376-383.

28. Bell SC, Saunders MJ, Elborn JS, Shale DJ. Resting energy expenditure and oxygen cost of breathing in patients with cystic fibrosis. Thorax. 1996;51(2):126-131.

29. Selvadurai HC, Allen J, Sachinwalla T, Macauley J, Blimkie CJ, Van Asperen PP. Muscle function and resting energy expenditure in female athletes with cystic fibrosis. Am J Respir Crit Care Med. 2003;168(12):14761480.

30. Ionescu AA, Mickleborough TD, Bolton CE, Lindley MR, Nixon LS, Dunseath G, Luzio S, et al. The systemic inflammatory response to exercise in adults with cystic fibrosis. J Cyst Fibros. 2006;5(2):105-112.

31. Davis PB. Therapy for cystic fibrosis--the end of the beginning? N Engl J Med. 2011;365(18):1734-1735.

32. Pitukcheewanont P, Safani D. Extremely low-level, short-term mechanical stimulation increases cancellous and cortical bone density and muscle mass of children with low bone density: a pilot study. The Endocrinologist, 2006. 16(3): 128.

33. Fagnani F, Giombini A, Di Cesare A, Pigozzi F, Di Salvo $\mathrm{V}$. The effects of a whole-body vibration program on muscle performance and flexibility in female athletes. Am J Phys Med Rehabil. 2006;85(12):956-962.

34. Sands WA, McNeal JR, Stone MH, Russell EM, Jemni
M. Flexibility enhancement with vibration: Acute and long-term. Med Sci Sports Exerc. 2006;38(4):720-725.

35. Bautmans I, Van Hees E, Lemper JC, Mets T. The feasibility of Whole Body Vibration in institutionalised elderly persons and its influence on muscle performance, balance and mobility: a randomised controlled trial [ISRCTN62535013]. BMC Geriatr. 2005;5:17.

36. Kawanabe K, Kawashima A, Sashimoto I, Takeda T, Sato Y, Iwamoto J. Effect of whole-body vibration exercise and muscle strengthening, balance, and walking exercises on walking ability in the elderly. Keio J Med. 2007;56(1):28-33.

37. Bogaerts AC, Delecluse C, Claessens AL, Troosters T, Boonen S, Verschueren SM. Effects of whole body vibration training on cardiorespiratory fitness and muscle strength in older individuals (a 1-year randomised controlled trial). Age Ageing. 2009;38(4):448-454.

38. Bogaerts A, Delecluse C, Claessens AL, Coudyzer W, Boonen S, Verschueren SM. Impact of whole-body vibration training versus fitness training on muscle strength and muscle mass in older men: a 1-year randomized controlled trial. J Gerontol A Biol Sci Med Sci. 2007;62(6):630-635.

39. Torvinen S, Kannus P, Sievanen H, Jarvinen TA, Pasanen M, Kontulainen S, Nenonen A, et al. Effect of 8-month vertical whole body vibration on bone, muscle performance, and body balance: a randomized controlled study. J Bone Miner Res. 2003;18(5):876-884.

40. Rehn B, Lidstrom J, Skoglund J, Lindstrom B. Effects on leg muscular performance from whole-body vibration exercise: a systematic review. Scand J Med Sci Sports. 2007;17(1):2-11.

41. Rietschel E, van Koningsbruggen S, Fricke O, Semler O, Schoenau E. Whole body vibration: a new therapeutic approach to improve muscle function in cystic fibrosis? Int J Rehabil Res. 2008;31(3):253-256.

42. Roth J, Wust M, Rawer R, Schnabel D, Armbrecht G, Beller G, Rembitzki I, et al. Whole body vibration in cystic fibrosis--a pilot study. J Musculoskelet Neuronal Interact. 2008;8(2):179-187.

43. Roelants M, Delecluse C, Verschueren SM. Whole-bodyvibration training increases knee-extension strength and speed of movement in older women. J Am Geriatr Soc. 2004;52(6):901-908.

44. Cormie P, Deane RS, Triplett NT, McBride JM. Acute effects of whole-body vibration on muscle activity, strength, and power. J Strength Cond Res. 2006;20(2):257-261.

45. Erskine J, Smillie I, Leiper J, Ball D, Cardinale M. Neuromuscular and hormonal responses to a single session of whole body vibration exercise in healthy young men. Clin Physiol Funct Imaging. 2007;27(4):242-248.

46. Benson AC, Torode ME, Singh MA. Muscular strength and cardiorespiratory fitness is associated with higher 
insulin sensitivity in children and adolescents. Int J Pediatr Obes. 2006;1(4):222-231.

47. Siegel JA, Gilders RM, Staron RS, Hagerman FC. Human muscle power output during upper- and lower-body exercises. J Strength Cond Res. 2002;16(2):173-178.

48. Linthorne NP. Optimum release angle in the shot put. J Sports Sci. 2001;19(5):359-372.

49. Polgar G, Varuni P. Pulmonary function testing in children: techniques and standards. 1971: Saunders Philadelphia.

50. Hollenberg M, Tager IB. Oxygen uptake efficiency slope: an index of exercise performance and cardiopulmonary reserve requiring only submaximal exercise. J Am Coll Cardiol. 2000;36(1):194-201.

51. Rubin C, Pope M, Fritton JC, Magnusson M, Hansson T, McLeod K. Transmissibility of 15-hertz to 35-hertz vibrations to the human hip and lumbar spine: determining the physiologic feasibility of delivering low-level anabolic mechanical stimuli to skeletal regions at greatest risk of fracture because of osteoporosis. Spine (Phila Pa 1976). 2003;28(23):2621-2627.

52. Hedges LV, Olkin I. Statistical methods for meta-analysis. 1985: Academic Press New York.

53. Middel B, van Sonderen E. Statistical significant change versus relevant or important change in (quasi) experimental design: some conceptual and methodological problems in estimating magnitude of intervention-related change in health services research. Int J Integr Care. 2002;2:e15.

54. Rhea MR. Determining the magnitude of treatment effects in strength training research through the use of the effect size. J Strength Cond Res. 2004;18(4):918-920.

55. Baker MK, Atlantis E, Fiatarone Singh MA. Multimodal exercise programs for older adults. Age Ageing. 2007;36(4):375-381.
56. Faul F, Erdfelder E, Lang AG, Buchner A. G*Power 3: a flexible statistical power analysis program for the social, behavioral, and biomedical sciences. Behav Res Methods. 2007;39(2):175-191.

57. Delecluse C, Roelants M, Verschueren S. Strength increase after whole-body vibration compared with resistance training. Med Sci Sports Exerc. 2003;35(6):10331041.

58. Jordan MJ, Norris SR, Smith DJ, Herzog W. Vibration training: an overview of the area, training consequences, and future considerations. J Strength Cond Res. 2005;19(2):459-466.

59. Rittweger J, Schiessl H, Felsenberg D. Oxygen uptake during whole-body vibration exercise: comparison with squatting as a slow voluntary movement. Eur J Appl Physiol. 2001;86(2):169-173.

60. Schneiderman-Walker J, Wilkes DL, Strug L, Lands LC, Pollock SL, Selvadurai HC, Hay J, et al. Sex differences in habitual physical activity and lung function decline in children with cystic fibrosis. J Pediatr. 2005;147(3):321-326.

61. Cerny FJ. Relative effects of bronchial drainage and exercise for in-hospital care of patients with cystic fibrosis. Phys Ther. 1989;69(8):633-639.

62. Davis PB. The decline and fall of pulmonary function in cystic fibrosis: new models, new lessons. J Pediatr. 1997;131(6):789-790.

63. Gilsanz V, Wren TA, Sanchez M, Dorey F, Judex S, Rubin C. Low-level, high-frequency mechanical signals enhance musculoskeletal development of young women with low BMD. J Bone Miner Res. 2006;21(9):14641474 .

64. Ward K, Alsop C, Caulton J, Rubin C, Adams J, Mughal Z. Low magnitude mechanical loading is osteogenic in children with disabling conditions. J Bone Miner Res. 2004;19(3):360-369. 